\title{
Editorial
}

\section{Revistas Colombianas de Ingeniería: ¡Uníos!}

Tal como había sido anunciado, Colciencias se encuentra sensibilizando a la comunidad sobre la inminente puesta en marcha del nuevo modelo de indexación de publicaciones seriadas de ciencia tecnología e innovación - Publindex. Aunque la versión final difiere en algunos aspectos de la inicialmente planteada (ver nuestra nota editorial 2011-I, Vol.16, Num.1), el espíritu de la norma sigue siendo propender por aumentar los niveles de visibilidad e impacto de las publicaciones locales de acuerdo con los estándares de medición de índices bibliográficos internacionales (ISI, Scopus, y otras bases de datos bibliográficas). Los criterios más estrictos se refieren a aumentar la cota mínima de artículos de investigación (12 por año para C, 15 para B) y articular las categorías A1, A2, A3, A4 (aparecen estas dos últimas nuevas) a los cuartiles del índice de impacto de ISI o Scopus, y las categorías B y C a las bases de datos bibliográficas Scielo y Redalyc para el caso de ingeniería.

En nuestra opinión el espíritu de la normativa propuesta es noble en cuanto pretende fortalecer la dinámica de la divulgación científica en nuestro país, eliminar la endogamia y proyectar desde lo local hacia lo universal la transferencia de resultados de nuevo conocimiento e innovación tecnológica que logran nuestros investigadores. Sin embargo nos parece que solamente endurecer los criterios de indización no es suficiente. Pues no encontramos detrás de esta propuesta una política de acompañamiento de parte de Colciencias, de forma que se definan estrategias y recursos que respalden la adopción del nuevo modelo y que permitan a las revistas nacionales equipararse con sus pares internacionales. En este sentido persisten las dudas que nos planteábamos en dicho editorial: ¿cómo garantizar que la transición a referentes universales sea continua y no abrupta? Ya que para ello se requieren gestión, conocimiento, apoyo técnico y financiero por fuera del alcance de la mayoría de nuestras revistas en su grado de madurez actual, poniendo en riesgo de fracaso los procesos que en mayor o menor grado, han recorrido hasta el momento las revistas. Por otra parte, ¿'es viable medir efectivamente los alcances de impacto local y/o regional que puedan tener investigaciones sobre problemas inherentemente colombianos a través de índices internacionales, que por demás son manejados por compañías privadas con limitaciones de acceso libre para la comunidad? Creemos que no, mientras no se consolide una dinámica de reconocimiento y citación nacional de los trabajos publicados en nuestras revistas, que en la actualidad no ocurre debido a la proliferación que indirectamente causó el modelo Publindex anterior. Hoy en día tenemos prácticamente una o más revistas por cada facultad de ingeniería del país $(62)^{1}$, dispersando fortalezas y esfuerzos que de no unificarse, difícilmente podrán alcanzar la visibilidad requerida.

Finalmente, quizás la pregunta mas inquietante, ¿cuántas de nuestras revistas hoy en día cuentan con las estructuras de apoyo y madurez de procesos necesarias para alcanzar el nivel A del nuevo índice? Tres o cuatro es nuestra predicción, ubicándose a lo más en A4. Surge pues la inquietud: ¿Cuál es el horizonte avizorado

1 Número de revistas indexadas en Publindex en 2013, dentro de la gran área de conocimiento: ingenierías. 
por Colciencias para que las demás lleguen allí, o más aún, para que estas pocas suban hasta A1? Lastimosamente, luce oscuro. A menos que exista un proceso de crecimiento continuo respaldado con acompañamiento institucional, gremial, comunitario y estatal, que permita alcanzar visibilidad nacional a corto plazo (Colombia) y regional a mediano plazo (Latinoamérica). Aparte del modelo de medición, ¿cómo va a apoyar Colciencias tal proceso? Desde la Revista INGENIERÍA queremos lanzar una propuesta que contribuya a iniciar un debate que quizás contribuya a resolver estas preguntas. Partiremos de la premisa de que el nuevo modelo, a la luz de los cuestionamientos expresados, desvirtúa la naturaleza de contar con revistas multidisciplinares de ingeniería editadas por universidades o facultades con población objetivo local. La propuesta consiste pues, en buscar una fusión de ellas para dar origen a una «Revista Colombiana de Ingeniería» unificada, con secciones especializadas en las diversas ramas de la ingeniería que se practica en Colombia, con una periodicidad bimestral o mensual (según el número de especialidades), y editada con el apoyo de organizaciones científicas o gremiales nacionales. Con el ánimo de evitar posibles conflictos de interés o luchas de poder, la dirección editorial de esta nueva revista debería desprenderse de las universidades o instituciones editoriales actuales, para depositarla en un organismo imparcial encargado de realizar su gestión (proponemos por ejemplo a la Asociacion Colombiana para el Avance de la Ciencia - ACAC o a la Sociedad Colombiana de Ingenieros). En cuanto a los recursos financieros necesarios para su funcionamiento, consideramos que deberían ser provistos conjuntamente por Colciencias (como parte de la estrategia que respalde el nuevo modelo de medición) y ACOFI (como representante de facultades de ingeniería que agrupa y de las cuales recibiría aportes para este fin). En cuanto a los recursos humanos, obviamente serían aportados por las universidades y entidades editoras actuales, conformando equipos altamente calificados de editores, comités científicos y árbitros. La nueva Revista debería tener al menos un representante de cada institución. Al respecto se requeriría igualmente el compromiso de las instituciones para reconocer la profesionalización de la labor de los editores y revisores, autorizando por ejemplo, horas en sus planes de trabajo para los profesionales que contribuyan en dichas tareas. Por último, para evitar demoras en la periodicidad debido a inconvenientes con la impresión, se propone que la nueva Revista sea electrónica, y que Publindex la indexe inicialmente con la moda de las categorías de aquellas que se fusionen, con una validez no menor a 2 años mientras logra alcanzar los criterios de existencia requeridos por el nuevo modelo, antes de ser re-categorizada.

Suponemos también que esta iniciativa favorecería en mayor grado a las revistas que en la actualidad nos encontramos en categorías bajas de Publindex, que a las que se han consolidado con arduo trabajo en las más altas. Pero por otro lado reconocemos que el número de revistas en categorías $\mathrm{C}$ y $\mathrm{B}$ es mucho mayor que las de A1 y A2, por lo que se podría conformar masa crítica y sobre todo aunar las fortalezas de editores y comités editoriales que en ellas están dispersas, para que unificadas posibiliten su pronta ubicación en los índices internacionales. Nótese que la Revista unificada tendría fácilmente visibilidad nacional inmediata, con lo cual se viabiliza el fortalecimiento de su factor de impacto, en el corto plazo nacional, y en el mediano plazo, regional. Una vez fortalecida, podría convocar a las actuales A1 y A2 para intentar convertirse en un órgano de difusión científico de impacto universal, como lo pretende el nuevo modelo de medición.

Por el momento continuamos aportando con la presente edición, artículos sobre: sistemas difusos para coloración psicodélica, taxonomías de incidentes de seguridad informática, gestión de la cadena productiva del biodiesel, identificación de entidades nombradas en redes sociales y análisis de parámetros de ubicación y dimensionamiento en almacenes. Agradecemos sinceramente como siempre a nuestros autores, revisores y lectores. $\mathrm{Y}$ a la comunidad académica la exhortamos a reflexionar en torno a la conveniencia de unificar desde ya fortalezas, experiencias y entusiasmos.

Ing. Sergio A. Rojas, MSc., PhD. Editor General Revista INGENIERÍA 